\title{
Effects of somatic embryogenesis on gene expression of cloned coffee heterozygous hybrids
}

\author{
Kenia Carvalho de Oliveira ${ }^{1}$. Paula de Souza Guimarães ${ }^{1}$. Jaqueline Moraes Bazioli ${ }^{1}$. Juliana Camargo Martinati ${ }^{1}$. \\ Mariana Martinis dos Santos ${ }^{1} \cdot$ Lilian Padilha $^{2} \cdot$ Oliveiro Guerreiro-Filho $^{1} \cdot$ Mirian Perez Maluf $^{2}$ (1)
}

Received: 3 October 2018 / Revised: 9 January 2019 / Accepted: 3 June 2019

(c) Franciszek Górski Institute of Plant Physiology, Polish Academy of Sciences, Kraków 2019

\begin{abstract}
Key Message Our analyses suggest that no major genome organization occurred during SE process implying the nonoccurrence of somaclonal variation. However, the genetic background determines the quality of the in vitro response. Abstract Cloning of superior coffee plants by somatic embryogenesis can assist breeding programs on reducing the cost and time for launch of new cultivars. This study aimed to evaluate the efficiency of this methodology for cloning coffee trees with high heterozygosity, and to gather evidence that clonal progenies are faithful copies of mother plants. Selected plants IAC 1 and IAC 2 from Coffea arabica breeding populations, resistant to leaf rust and leaf miner, respectively, were cloned via indirect somatic embryogenesis. Expression of selected genes involved in biological processes potentially affected by in vitro cultivation was evaluated by quantitative analysis. Genes encoding proteins associated with maintenance of DNA integrity and control of cell cycle presented predictable expression patterns along the clonal multiplication process. There were differences in the expression pattern of genes linked to in vitro cultivation-related stress, which were observed comparing either IAC 1 and IAC2 genotypes or clones and their corresponding mother plant. Those analyses suggest that the somatic embryogenesis does not lead to major genomic instability and clones are identical copies of mother plants, even with detected differences in the expression of genes that influence the response of in vitro cultivation.
\end{abstract}

Keywords Coffea arabica $\cdot$ In vitro cultivation $\cdot$ Differential expression $\cdot$ Somaclonal variation

\section{Introduction}

Coffee cultivation, processing, marketing, and transportation have long been considered as significant factors for socioeconomic growth and development, as they provide millions of job opportunities around the world. However, the cost of coffee production is high due to several features, including the occurrence of biotic and abiotic stresses, and the operational costs of manual or mechanical harvest. In addition, the long cycle of the crop, the low genetic variability within the species, and the need for several years of production to evaluate adverse conditions throughout productivity cycle,

Communicated by J. Van Huylenbroeck.

Mirian Perez Maluf

mirian.maluf@embrapa.br

Coffee Center Agronomic Institute/IAC, Campinas, Brazil

2 EMBRAPA and Coffee Center Agronomic Institute/IAC, Campinas, Brazil are among stimulus to use genetic improvement for developing novel productive and resistant cultivars.

Plant tissue culture techniques applied to coffee breeding are important tools for maintenance and evaluation of germplasm, genomic-assisted selection, identification of new genus, and, finally, multiplication of special coffee genotypes (Bertrand et al. 2011; Shahzad et al. 2017). Furthermore, breeding programs have available extremely promising agronomic $\mathrm{F} 1$ hybrid plants combining disease resistance and insect tolerance that are yet heterozygous, and, therefore, not suitable for seed multiplication. The exploitation of this heterozygosis in coffee may be possible with cloning processes such as somatic embryogenesis.

Somatic embryogenesis aims to regenerate identical plants from the parent plant, considering the concept of cellular totipotency (Pereira et al. 2007). The somatic embryogenesis in coffee occurs through two developmental pathways: direct somatic embryogenesis, in which somatic embryos originated directly from the mother tissues without the formation of intermediate stages of callus (Gaj 2004); 
and indirect, where somatic embryos originated from callus, a mass of cells with disorganized growth. The methodology of indirect somatic embryogenesis is the most promising in coffee, but still requires studies for adaptation to the reality of large-scale production (Donato et al. 2000; MenéndezYuffá et al. 2010).

Cloning of special Arabica coffee plants is a strategy that can shorten the time for launching new cultivars as well as exploit their hybrid vigor. However, the use of embryogenic cell suspensions has often been associated with a likelihood of genetic instability and somaclonal variation. This phenomenon results in the development of phenotypic changes associated with genomic re-arrangements, resulting in plants different from the parent plant. Thus, somaclonal variation has become a major concern in plant propagation as it may lead to loss of genetic fidelity. Somaclonal variation mostly occurs as a response to the stress imposed on the plant in culture conditions, in the form of DNA methylations, chromosome re-arrangements, and point mutations (Phillips et al. 1994). Therefore, a stringent quality check in terms of genetic similarity of the progeny and an efficient and feasible cloning protocol become mandatory for the analysis of these types of plants. Landey et al. (2013) performed a largescale study using embryogenic suspensions and secondary embryogenesis for the multiplication of elite F1 hybrids of C. arabica. The molecular and phenotypical analyses indicated that the occurrence of somaclonal variation was very low, and possible genetic and epigenetic alterations occurred during somatic embryogenesis (Landey et al. 2013).

In this context, the objective of this work was to gather evidence that somatic embryogenic clones from two hybrid plants with high level of residual heterozygosity are faithful copies of their parent plants. Our strategy was to analyze the expression of genes potentially linked to the preservation of cell integrity and genetic material, as well as to stresses involved in the in vitro multiplication process. Expression patterns for 20 selected genes suggest that no major genome organization occurred during the SE process, which implies the nonoccurrence of significant somaclonal variation. However, our analyses show that the genetic background determines the quality of the in vitro response, as each hybrid exhibited different expression profiles especially for genes linked to stress response.

\section{Materials and methods}

\section{Plant material}

Somatic embryogenesis (SE) cultivation stages from two $C$. arabica genotypes belonging to the Coffee Breeding Program of IAC were collected. The genotypes were IAC 1, an $\mathrm{F}_{1}$ hybrid between Obatã and Icatu $C$. arabica cultivars, resistant to Hemileia vastatrix (leaf rust); and IAC 2, an $\mathrm{F}_{3} \mathrm{RC}_{4}$ line resistant to Leucoptera coffeella (leaf miner) and derived from a recombination between $C$. arabica $\mathrm{L}$. and $C$. racemosa $\mathrm{L}$. species.

Plants were in vitro cultivated by SBW, a commercial company (SBW 2018, http://www.sbwbrasil.com.br/). The SBW team developed the in vitro culture conditions and protocols for indirect somatic embryogenesis. Upon SE completion, developed embryos were transferred to proper substrate and kept at greenhouses conditions to grow into emblings. Samples corresponding to the SE stages embryogenic callus, multiplication, differentiation, maturation, germination, and embryo formation (Fig. 1) were collected for gene expression analyses. Table 1 summarizes the overall response of each genotype. On average, six petri dishes of each stage were sampled for each genotype. In addition, leaf samples from IAC 1 and IAC 2 mother plants and nursery emblings
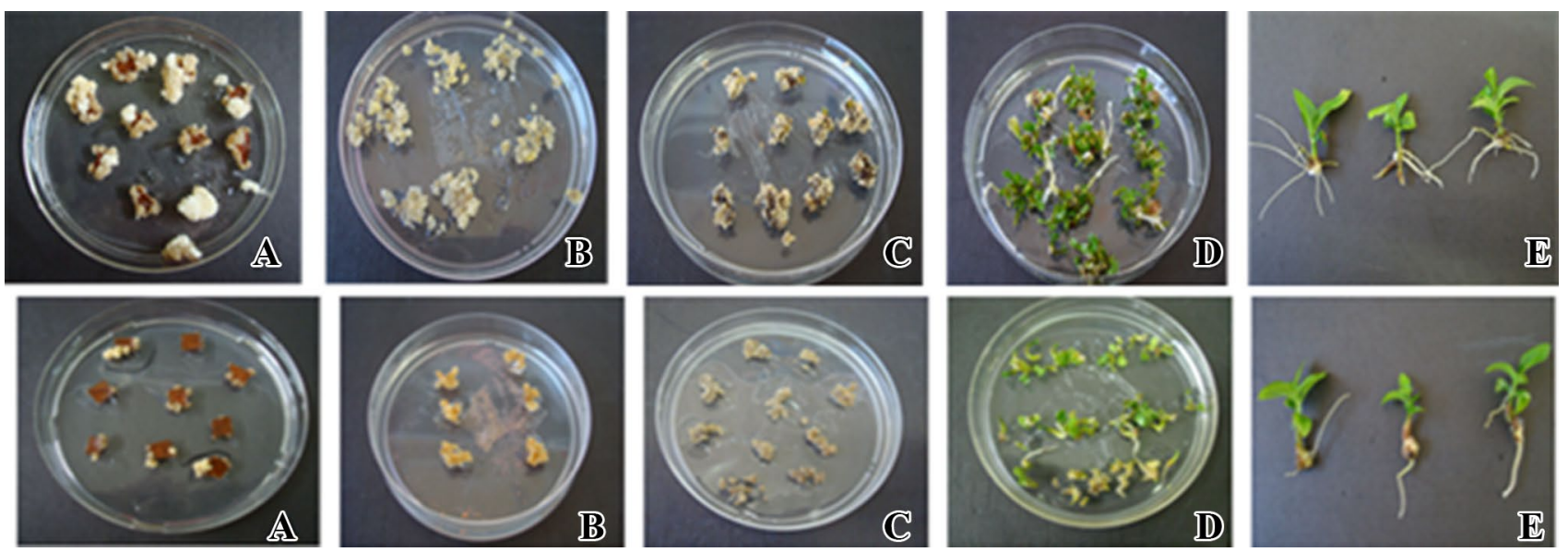

Fig. 1 Development stages during in vitro cultivation of IAC 1 (top) leaf-rust resistant; and IAC 2 (bottom) leaf-miner resistant. a callus; b multiplication; $\mathbf{c}$ differentiation; $\mathbf{d}$ maturation; $\mathbf{e}$ in vitro emblings 
Table 1 Summary of phenotypic characteristics from coffee clones developed by indirect somatic embryogenesis

\begin{tabular}{lll}
\hline Parameters & Clones & \\
\cline { 2 - 3 } & IAC 1 & IAC 2 \\
\hline Callus aspect & Friable, hyaline & Compact, oxidized \\
Earliness of development & Normal & Late \\
Synchronism of growth & High & Medium \\
Productivity & High & Medium \\
\hline
\end{tabular}

were also collected. The samples were frozen in liquid nitrogen $\left(\mathrm{N}_{2}\right)$, and stored in freezer $-80{ }^{\circ} \mathrm{C}$ until needed.

\section{Identification of coffee ESTs and gene-specific primers selection}

Genes associated with major genomic re-arrangements, DNA integrity, cell maintenance and cycle regulation, and somatic embryogenesis responsiveness were evaluated here. Gene sequences were retrieved from the GenBank and used in directed Blast searches in Brazilian Coffee Genome Database (Altschul et al. 1990; Vieira et al. 2006). A list of selected genes, access number, and functional grouping is presented in Table 2. Homolog coffee ESTs were identified based on stringent similarity parameters such as $e$-value $<e^{-20}$, presence of protein-specific domains, and relative abundance on libraries from in vitro coffee cell cultures. To select gene-specific primers, ESTs sequences were clustered and re-aligned with corresponding genes, and highly conserved regions were identified using public databases (http://www.ncbi.nlm.nih.gov/cdd; http://pfam.sange r.ac.uk/). Coffee-based primer pairs were selected using Primer 3 (http://frodo.wi.mit.edu/primer3/).

Primer efficiency was established in DNA and cDNA samples according to defined parameters: single amplicon upon dissociation analysis, standard curve slope between -3.5 and -3.2 , and amplification efficiency between 0.93 and 1.05 .

\section{Gene-expression analyses}

Total RNA was extracted from $300 \mu \mathrm{g}$ of frozen tissues using a Trizol-based protocol (Applied Biosystems). RNA quantification was performed by formaldehyde-agarose electrophoresis and absorbance at 220-340 nm using a Shimadzu UV spectrophotometer.

Gene-expression analysis was evaluated by quantitative RT-PCR (qPCR). A total of $2 \mu \mathrm{g}$ RNA DNAase-free of each sample were used for cDNA synthesis using the commercial Kit SuperScript III First-Strand Synthesis SuperMix (Life Technologies). Quantitative RT-PCR was performed in an AB7300 System (Applied Biosystems) using the Sybr Green
Kit (Life Technologies), which include both SYBR green and passive reference ROX fluorescence. Reaction conditions are the same as described elsewhere, using $200 \mathrm{ng}$ of cDNA (Maluf et al. 2009). To confirm the presence of single amplicons, all PCR products were analyzed through a dissociation curve, with temperature varying from 60 to $95^{\circ} \mathrm{C}$. qPCR results were analyzed with the sequence detection software SDS version 1.3.1 (Applied Biosystems), and transcript abundance was estimated using defined threshold value, baseline, and Ct parameters (Maluf et al. 2009). The GAPDH gene was used as the endogenous control (F-TTG AAGGGCGGTGCAAA; R- AACATGGGTGCATCCTTG CT). Relative expression quantification was calculated using average values of three replicates, for each stage, where each amplification was performed using a fresh cDNA pool. Relative expression was calculated using plant mother of each genotype as the calibrator sample.

\section{Results}

To understand the molecular basis of in vitro culture in coffee, we selected genes from different biological processes to analyze their expression profile by the qPCR technique (Table 2). Selected biological process included the maintenance of DNA integrity, control of cell division and cell cycle, response to oxidative stress derived from in vitro culture, and biotic and abiotic stresses.

Gene-expression analyses comprised the different stages of SE such as mother plant, embryogenic callus, multiplication and differentiation phase, maturation, and germination phase, in vitro and nursery emblings (Fig. 1). Table 3 exhibits the results of relative gene expression on each genotype. For these analyses, the calibrator stage was the original genotypes used for somatic embryogenesis, the mother plant. The expression values represent at least three independent estimates, for each gene and developmental stage. The analyses indicated that the SE process affected distinctly IAC 1 and IAC2, as each genotype exhibited a different gene expression profile.

We identified three different expression patterns between IAC 1 and IAC 2. For most of the evaluated genes, expression differences between the genotypes result from variations on overall expression levels, as shown in Fig. 2, for DNAmet, EST1 and PPO. Genes that also exhibited this profile are Cell Div, EDS, H2A, IA, Oxired_NADH, AP2, PPT, RNA H, TIFY, and $\beta$-TUB. A second difference observed is a shift on which developmental stage occurs the higher gene-expression level. In this case, CELL, EMF-2, JAZ, LEA, and Wuschel transcripts accumulated at higher levels on different in vitro stages of IAC 1 and IAC 2 (Fig. 3 and Table 3). A third profile includes genes with different 
Table 2 List of genes with corresponding accession number, biological process, and specific primers

\begin{tabular}{|c|c|c|c|}
\hline Gene name & Blast & Biological role & Primers \\
\hline AP2/apetala-2 & AT4G36920 & Plant organ morphogenesis & $\begin{array}{l}\text { F: 5' GTTTCGGGCAGTCCATACTC 3' } \\
\text { R: 5' CCTCCTCCTTACCCCTCTGT 3' }\end{array}$ \\
\hline$\beta$-TUB $/ \beta$-Tubulin & AY081473 & Nuclear division & $\begin{array}{l}\text { F: 5' GCACGGAGCACACTTCAATA 3' } \\
\text { R: 5' TGGTTGTTGAAATCAGGTGGT } \\
\text { 3' }\end{array}$ \\
\hline $\mathrm{CaDXMT/caffeine} \mathrm{synthase}$ & AB084125 & Secondary metabolism & $\begin{array}{l}\text { F: 5' AAAGGGAGCATTTACTCTTCC } \\
\text { AAAG 3' } \\
\text { R: 5' AGCATGCATCCTGAGAAATGT } \\
\text { GGTA 3' }\end{array}$ \\
\hline CELL/anaphase promoting complex & XP_011098213 & Cellular division & $\begin{array}{l}\text { F: 5' AGAAGGCCCTGTCATGGTTT 3' } \\
\text { R: 5' TGCTGAAATAGCGACGTGAC 3' }\end{array}$ \\
\hline Cell Div/cell division 48 & XP_021627792 & Cellular division & $\begin{array}{l}\text { F: 5' CTCTGCTTTGCGTGAGACAG 3' } \\
\text { R: 5' GAACTTCTCCGGATGTTCCA 3' }\end{array}$ \\
\hline DNA Met/dna methyltransferase & AM946610 & DNA methylation & $\begin{array}{l}\text { F: 5' GGTGGAATGGGATCCAGATA 3' } \\
\text { R: 5' GTGAGGTTCTGCTCGTGTGA 3' }\end{array}$ \\
\hline EDS/enhanced disease susceptibility & NP_001307178 & Response to biotic stimulus & $\begin{array}{l}\text { F: 5' TGAAGTGCGCAAGGTAGGT 3' } \\
\text { R: 5' AGGTTCAACCAACCGCCTA 5' }\end{array}$ \\
\hline EMF-2/embryonic flower 2 & ACV87734 & Regulation of reproductive development & $\begin{array}{l}\text { F: 5' ACATTGCACCTCCAACTGTG 3' } \\
\text { R: 5' CTCTTCTGCAACAGCAAACG 3' }\end{array}$ \\
\hline EST1/telomerase activating & AF135454 & Telomere maintenance & $\begin{array}{l}\text { F: 5' TTGTGGACCTTCAAGAGGTTG } \\
\text { 3' } \\
\text { R: 5' CCTCATGCTTTTGCGAAACT 3' }\end{array}$ \\
\hline GYF/protein19 analog & OIT08406 & $\begin{array}{l}\text { DNA binding } \\
\text { Response to abiotic stimulus }\end{array}$ & $\begin{array}{l}\text { F: 5' TCAGACAAGAATCGGGAACC 3' } \\
\text { R: 5' TGATTGTCACTGGCATCCTC 3' }\end{array}$ \\
\hline $\mathrm{H} 2 \mathrm{~A} /$ histone 2 & LOC107004541 & Chromosome organization & $\begin{array}{l}\text { F: 5' CGTACGAAGCAGACTGCAAG 3' } \\
\text { R: 5' CTTCTTCACTCCTCCGGTTG 3' }\end{array}$ \\
\hline IA/apoptose inhibitor & XP_011098257 & Regulation of apoptotic process & $\begin{array}{l}\text { F: 5' AGTGCTACCTCTGGGCTCAA } 3 \\
\text { R: 5' ACCCCCAATAAAGGAAGGTG 3' }\end{array}$ \\
\hline LEA/late embryogenesis abundant & AAY26119 & Response to abiotic stimulus & $\begin{array}{l}\text { F: 5' GTAGCTGCTTCGGCAAAGTC 3' } \\
\text { R: 5' TTTCCTCTTTCTTCCGCTCA 3' }\end{array}$ \\
\hline $\begin{array}{l}\text { OXIRED_NADH/NADH oxidoreduc- } \\
\text { tase }\end{array}$ & YP_817535 & Oxidation/reduction process & $\begin{array}{l}\text { F: 5' CGAATCGATTGCATTGAGG 3' } \\
\text { R: 5' CGAGCATCATTAACCAACTCC } \\
3^{\prime}\end{array}$ \\
\hline $\mathrm{PPO} /$ polyphenol oxidase & BAA92317 & Oxidation/reduction process & $\begin{array}{l}\text { F: 5' CCCCTTAACAAGACCGTGAA 3' } \\
\text { R: 5' CGGACACCACCAATCTCTCT 3' }\end{array}$ \\
\hline $\mathrm{PPT} /$ signal-peptide peptidase & EOY04905 & Protein metabolic process & $\begin{array}{l}\text { F: 5' ACTTCCTTTGGTTGGCCATT 3' } \\
\text { R: 5' GGAGAGCAGGTTGACCATGT 3' }\end{array}$ \\
\hline RNA H/RNA helicase & XP_021644395 & Nucleic acid binding & $\begin{array}{l}\text { F: 5' AGGCATATTGTCCTGCCTTG 3' } \\
\text { R: 5' GGCAATAAGCCAGCAAGTTC 3' }\end{array}$ \\
\hline $\begin{array}{l}\text { SERK/Somatic embryogenic receptor } \\
\text { kinase }\end{array}$ & PHU30048 & Regulation of cellular process & $\begin{array}{l}\text { F: 5' TGTACTCGTCTTTGCGCTTG 3' } \\
\text { R: 5' GATCTGCCAAGCTGACCTTC 3' }\end{array}$ \\
\hline JAZ/jasmonate zim domain protein & ALI87031 & $\begin{array}{l}\text { Response to biotic stimulus } \\
\text { Biological regulation }\end{array}$ & $\begin{array}{l}\text { F: 5' GGAGCTCCAGCTCAGTTGAC 3' } \\
\text { R: 5' TGCATTTCCAGCCAATAACA }\end{array}$ \\
\hline Wuschel & EOY10442 & Embryo development & $\begin{array}{l}\text { F: 5' GACTCCCAAACCAGAGCAAA 3' } \\
\text { R: 5' CACCCACAGAACCGAATTTT 3' }\end{array}$ \\
\hline
\end{tabular}

patterns of transcript accumulation along SE, such as CS and SERK (Fig. 4).

The most relevant differences are those on expression of genes associated with differentiation and organogenesis, such as Wuschel, SERK, and EMF-2. For those genes, expression pattern on IAC 1 and IAC 2 may explain the observed phenotypic differences on the overall in vitro culture efficiency (Table 1). On IAC 1, Wuschel peaks during maturation and germination phase, one stage after the expression peak observed on IAC 2, which is multiplication and differentiation. For EMF-2, a delayed peak also occurs for IAC 1, at multiplication and differentiation, when compared with the peak at embryogenic callus on IAC 2 . The expression pattern for the gene SERK is inverted, as in IAC 1 expression levels increased in stages such as embryogenic callus and in vitro emblings, and in IAC 2, the expression 
Table 3 Values for relative quantification of gene expression along SE process, considering Mother Plant as the calibrator stage

\begin{tabular}{|c|c|c|c|c|c|c|c|}
\hline Gene ID & Genotype & Mother plant & Embryogenic callus & $\begin{array}{l}\text { Multiplication } \\
\text { and differentia- } \\
\text { tion }\end{array}$ & $\begin{array}{l}\text { Maturation and } \\
\text { germination }\end{array}$ & In vitro embling & Nursery embling \\
\hline \multirow[t]{2}{*}{ AP2 } & IAC 1 & 1.00 & $0.058 \pm 0.002$ & $0.261 \pm 0.19$ & $0.103 \pm 0.03$ & $1.076 \pm 0.09$ & $1.094 \pm 0.09$ \\
\hline & IAC2 & 1.00 & $0.457 \pm 0.385$ & $0.194 \pm 0.03$ & $0.331 \pm 0.04$ & $1.695 \pm 0.05$ & $3.876 \pm 0.84$ \\
\hline \multirow[t]{2}{*}{ CaDXMT } & IAC 1 & 1.00 & $0.681 \pm 0.28$ & $230.09 \pm 5.45$ & $5.405 \pm 0.75$ & $1.328 \pm 0.10$ & $0.686 \pm 0.13$ \\
\hline & IAC2 & 1.00 & $0.118 \pm 0.03$ & $0.127 \pm 0.02$ & $0.412 \pm 0.04$ & $0.571 \pm 0.01$ & $0.002 \pm 0.001$ \\
\hline \multirow[t]{2}{*}{ CELL } & IAC 1 & 1.00 & $6.952 \pm 1.44$ & $5.946 \pm 1.67$ & $4.145 \pm 2.42$ & $2.023 \pm 0.85$ & $3.828 \pm 1.52$ \\
\hline & IAC2 & 1.00 & $8.519 \pm 3.47$ & $3.097 \pm 1.57$ & $2.077 \pm 0.93$ & $2.785 \pm 1.49$ & $4.267 \pm 1.79$ \\
\hline \multirow[t]{2}{*}{ Cell Div } & IAC 1 & 1.00 & $0.794 \pm 0.08$ & $0.551 \pm 0.14$ & $0.440 \pm 013$ & $0.808 \pm 0.06$ & $1.117 \pm 0.17$ \\
\hline & IAC2 & 1.00 & $1.288 \pm 0.25$ & $0.690 \pm 0.12$ & $0.337 \pm 0.05$ & $0.706 \pm 0.18$ & $0.971 \pm 0.03$ \\
\hline \multirow[t]{2}{*}{ DNA Met } & IAC 1 & 1.00 & $150.655 \pm 52.57$ & $134.196 \pm 57.60$ & $76.886 \pm 29.24$ & $22.508 \pm 14.382$ & $1.645 \pm 0.47$ \\
\hline & IAC2 & 1.00 & $263.550 \pm 31.78$ & $19.505 \pm 3.61$ & $52.998 \pm 19.62$ & $3.969 \pm 1.13$ & $51.434 \pm 36.90$ \\
\hline \multirow[t]{2}{*}{ EDS } & IAC 1 & 1.00 & $0.083 \pm 0.03$ & $0.161 \pm 0.04$ & $0.257 \pm 0.10$ & $0.414 \pm 0.10$ & $0.349 \pm 0.001$ \\
\hline & IAC2 & 1.00 & $0.422 \pm 0.21$ & $0.473 \pm 0.10$ & $0.240 \pm 0.06$ & $0.466 \pm 0.13$ & $0.277 \pm 0.06$ \\
\hline \multirow[t]{2}{*}{ EMF-2 } & IAC 1 & 1.00 & $2.190 \pm 0.36$ & $1.364 \pm 0.017$ & $1.864 \pm 1.26$ & $2.059 \pm 0.47$ & $0.755 \pm 0.08$ \\
\hline & IAC2 & 1.00 & $2.540 \pm 0.73$ & $1.249 \pm 0.87$ & $0.760 \pm 0.50$ & $1.052 \pm 0.80$ & $0.690 \pm 0.44$ \\
\hline \multirow[t]{2}{*}{ EST1 } & IAC 1 & 1.00 & $1.327 \pm 1.07$ & $0.943 \pm 0.67$ & $0.960 \pm 0.00$ & $1.370 \pm 1.40$ & $1.104 \pm 1.09$ \\
\hline & $\mathrm{IAC} 2$ & 1.00 & $0.450 \pm 0.07$ & $0.469 \pm 0.05$ & $0.632 \pm 0.18$ & $1.524 \pm 0.07$ & $0.602 \pm 0.23$ \\
\hline \multirow[t]{2}{*}{ GFY } & IAC 1 & 1.00 & $1.567 \pm 0.06$ & $1.728 \pm 0.06$ & $1.081 \pm 0.33$ & $0.872 \pm 0.02$ & $1.117 \pm 0.22$ \\
\hline & IAC2 & 1.00 & $3.545 \pm 0.30$ & $0.899 \pm 0.31$ & $0.807 \pm 0.17$ & $0.887 \pm 0.38$ & $1.008 \pm 0.39$ \\
\hline \multirow[t]{2}{*}{$\mathrm{H} 2 \mathrm{~A}$} & IAC 1 & 1.00 & $141.084 \pm 53.57$ & $88.219 \pm 31.26$ & $63.075 \pm 24.29$ & $24.948 \pm 12.49$ & $2.761 \pm 0.59$ \\
\hline & IAC2 & 1.00 & $37.860 \pm 0.65$ & $7.652 \pm 1.22$ & $5.432 \pm 0.78$ & $9.596 \pm 5.35$ & $1.571 \pm 1.03$ \\
\hline \multirow[t]{2}{*}{ IA } & IAC 1 & 1.00 & $1.629 \pm 0.37$ & $1.634 \pm 0.35$ & $1.379 \pm 0.31$ & $1.949 \pm 0.65$ & $2.274 \pm 0.70$ \\
\hline & IAC2 & 1.00 & $1.645 \pm 0.31$ & $0.982 \pm 0.11$ & $0.767 \pm 0.08$ & $1.069 \pm 0.37$ & $1.697 \pm 0.34$ \\
\hline \multirow[t]{2}{*}{ LEA } & IAC 1 & 1.00 & $31.902 \pm 15.43$ & $99.890 \pm 93.76$ & $2077.86 \pm 25.46$ & $2862.78 \pm 527.83$ & $7.383 \pm 0.06$ \\
\hline & IAC2 & 1.00 & $60.170 \pm 5.21$ & $112.54 \pm 12.32$ & $146.93 \pm 21.07$ & $4.11 \pm 0.73$ & $1.05 \pm 0.19$ \\
\hline \multirow[t]{2}{*}{ OXIRED_NADH } & IAC 1 & 1.00 & $0.038 \pm 0.003$ & $0.080 \pm 0.009$ & $0.090 \pm 0.012$ & $0.227 \pm 0.037$ & $0.414 \pm 0.07$ \\
\hline & $\mathrm{IAC} 2$ & 1.00 & $0.076 \pm 0.010$ & $0.068 \pm 0.058$ & $0.157 \pm 0.134$ & $0.425 \pm 0.368$ & $0.046 \pm 0.08$ \\
\hline \multirow[t]{2}{*}{$\mathrm{PPO}$} & IAC 1 & 1.00 & $0.416 \pm 0.21$ & $0.220 \pm 0.09$ & $1.957 \pm 0.45$ & $3.780 \pm 1.78$ & $0.419 \pm 0.20$ \\
\hline & IAC2 & 1.00 & $0.762 \pm 0.13$ & $0.368 \pm 0.05$ & $1.173 \pm 0.70$ & $1.677 \pm 0.84$ & $0.372 \pm 0.14$ \\
\hline \multirow[t]{2}{*}{ PPT } & IAC 1 & 1.00 & $2.472 \pm 0.26$ & $1.219 \pm 0.07$ & $0.931 \pm 0.14$ & $1.179 \pm 0.32$ & $1.743 \pm 0.90$ \\
\hline & IAC2 & 1.00 & $2.750 \pm 0.48$ & $0.793 \pm 0.08$ & $0.551 \pm 0.04$ & $1.146 \pm 0.23$ & $1.147 \pm 0.19$ \\
\hline \multirow[t]{2}{*}{ RNA H } & IAC 1 & 1.00 & $0.391 \pm 0.07$ & $0.848 \pm 0.23$ & $2.077 \pm 0.52$ & $3.394 \pm 1.68$ & $0.999 \pm 0.44$ \\
\hline & $\mathrm{IAC} 2$ & 1.00 & $0.567 \pm 0.38$ & $1.064 \pm 0.05$ & $0.447 \pm 0.04$ & $0.699 \pm 0.08$ & $0.849 \pm 0.27$ \\
\hline \multirow[t]{2}{*}{ SERK } & IAC 1 & 1.00 & $9.247 \pm 3.49$ & $2.376 \pm 0.08$ & $5.579 \pm 0.13$ & $25.747 \pm 6.45$ & $1.209 \pm 0.19$ \\
\hline & IAC2 & 1.00 & $4.025 \pm 0.60$ & $13.384 \pm 4.05$ & $12.119 \pm 6.92$ & $9.888 \pm 3.61$ & $1.175 \pm 1.03$ \\
\hline \multirow[t]{2}{*}{ JAZ } & IAC 1 & 1.00 & $1.173 \pm 0.51$ & $0.712 \pm 0.02$ & $1.533 \pm 0.33$ & $2.063 \pm 0.40$ & $0.801 \pm 0.44$ \\
\hline & IAC2 & 1.00 & $1.498 \pm 0.87$ & $1.011 \pm 0.49$ & $0.560 \pm 0.28$ & $0.831 \pm 0.45$ & $0.290 \pm 0.14$ \\
\hline \multirow[t]{2}{*}{ Wuschel } & IAC 1 & 1.00 & $16.95 \pm 6.03$ & $34.00 \pm 12.53$ & $392.90 \pm 157.64$ & $268.54 \pm 121.69$ & 0.00 \\
\hline & IAC2 & 0.00 & 1.00 & $26.57 \pm 12.75$ & $14.60 \pm 4.83$ & $2.271 \pm 0.10$ & $0.258 \pm 0.17$ \\
\hline \multirow[t]{2}{*}{$\beta$-TUB } & IAC 1 & 1.00 & $0.195 \pm 0.09$ & $0.164 \pm 0.06$ & $1.005 \pm 0.21$ & $1.623 \pm 0.93$ & $1.600 \pm 0.03$ \\
\hline & IAC2 & 1.00 & $0.313 \pm 0.13$ & $0.104 \pm 0.03$ & $1.127 \pm 0.34$ & $2.073 \pm 0.42$ & $2.768 \pm 0.69$ \\
\hline
\end{tabular}

levels are lower at those stages. These differences on genes important for in vitro culture may explain the relative higher efficiency of IAC 1 to produce healthy emblings.

Besides genes related to organogenesis, we evaluated other biological aspects potentially related to somaclonal variations between mother and clonal plants. Among these, DNA methylation is an important issue during in vitro culture due to its association with gene silencing. The maximum expression level of a DNAmet gene occurs during the embryogenic phase for both IAC 1 and IAC 2. However, transcription levels remain high at the 
Fig. 2 Relative quantification of gene expression along SE process considering Mother Plant as the calibrator stage. Examples of profiles displaying differences on transcript levels
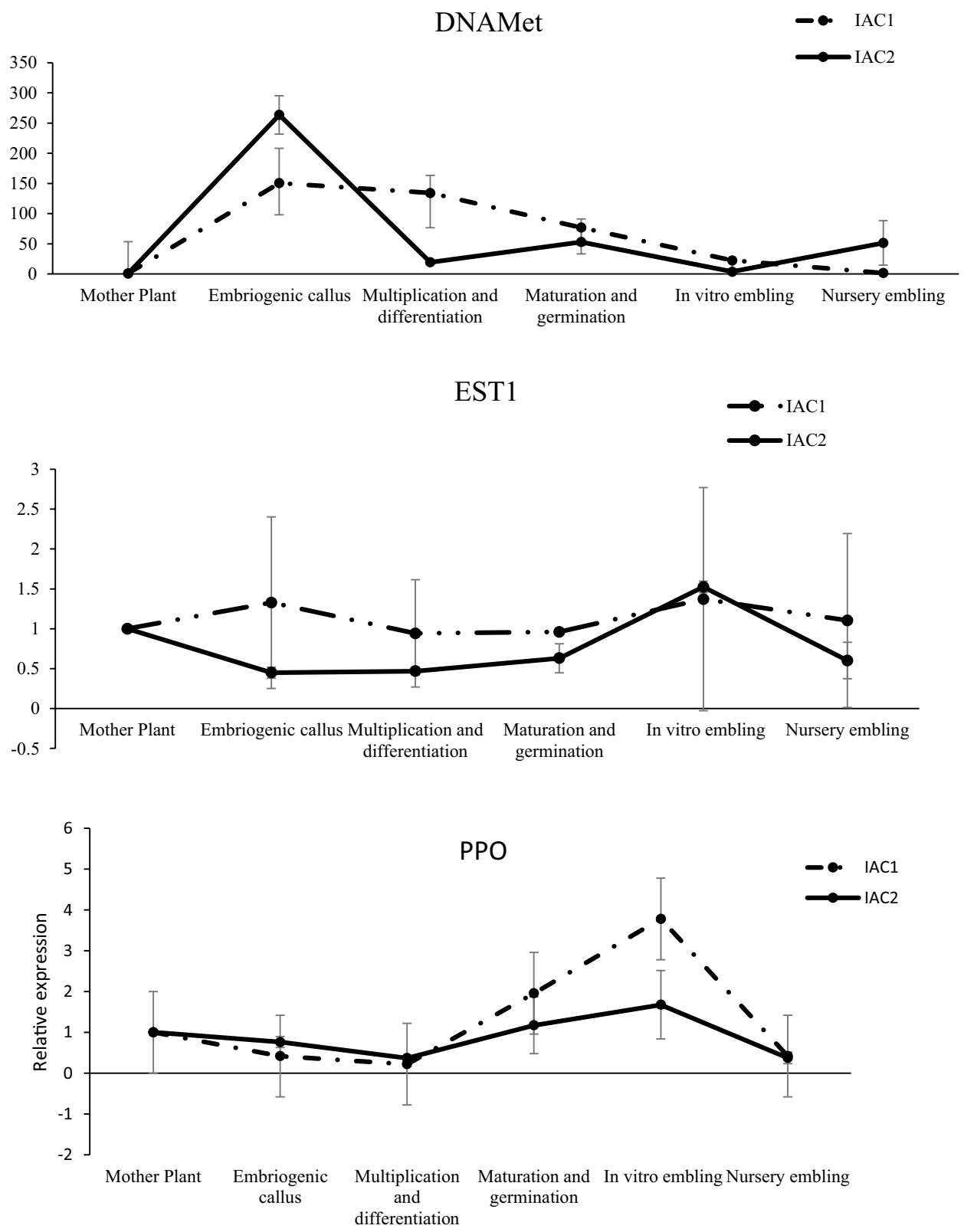

multiplication and differentiation stage on IAC 1, and drop at this stage on IAC 2 (Fig. 2).

Due to the potential stress caused by SE, we also evaluated genes responsive to desiccation (LEA) and from secondary metabolism (PPO and CS). LEA expression increases along in vitro culture in both genotypes, but, at IAC 1, the levels are higher up to the nursery embling stage, a step forward compared to IAC 2 (Fig. 3). These observed levels on IAC 1 nursery emblings are also higher than the levels on their mother plants.

Among all evaluated genes, $\mathrm{CS}$ is the one with the most divergent profile between IAC 1 and IAC 2 (Fig. 4). Not only the overall levels are much higher in IAC 1 , but also the expression profile is completely different: transcript levels on IAC 1 are low, with an increase at the multiplication and differentiation stage, and decrease rapidly on the following stages; at IAC 2, transcript levels are very low and decrease along in vitro cultivation. Although caffeine is the major compound in coffee plants, its role on plant physiology is not clear, and therefore, those observed differences may be or not relevant at these stages.

To assess possible effects of SE on expected agronomic traits, we also compared gene-expression levels on mother plants and emblings. Transcript levels are expected to be steady at similar environments, in both mother and clonal plants. As clonal plants were not available at the time, we checked the embling expression. For almost all evaluated genes, embling transcript levels are close to those 
Fig. 3 Relative quantification of gene expression along SE process considering the Mother Plant as the calibrator stage for each genotype. Examples of profiles displaying differences on peaking stage
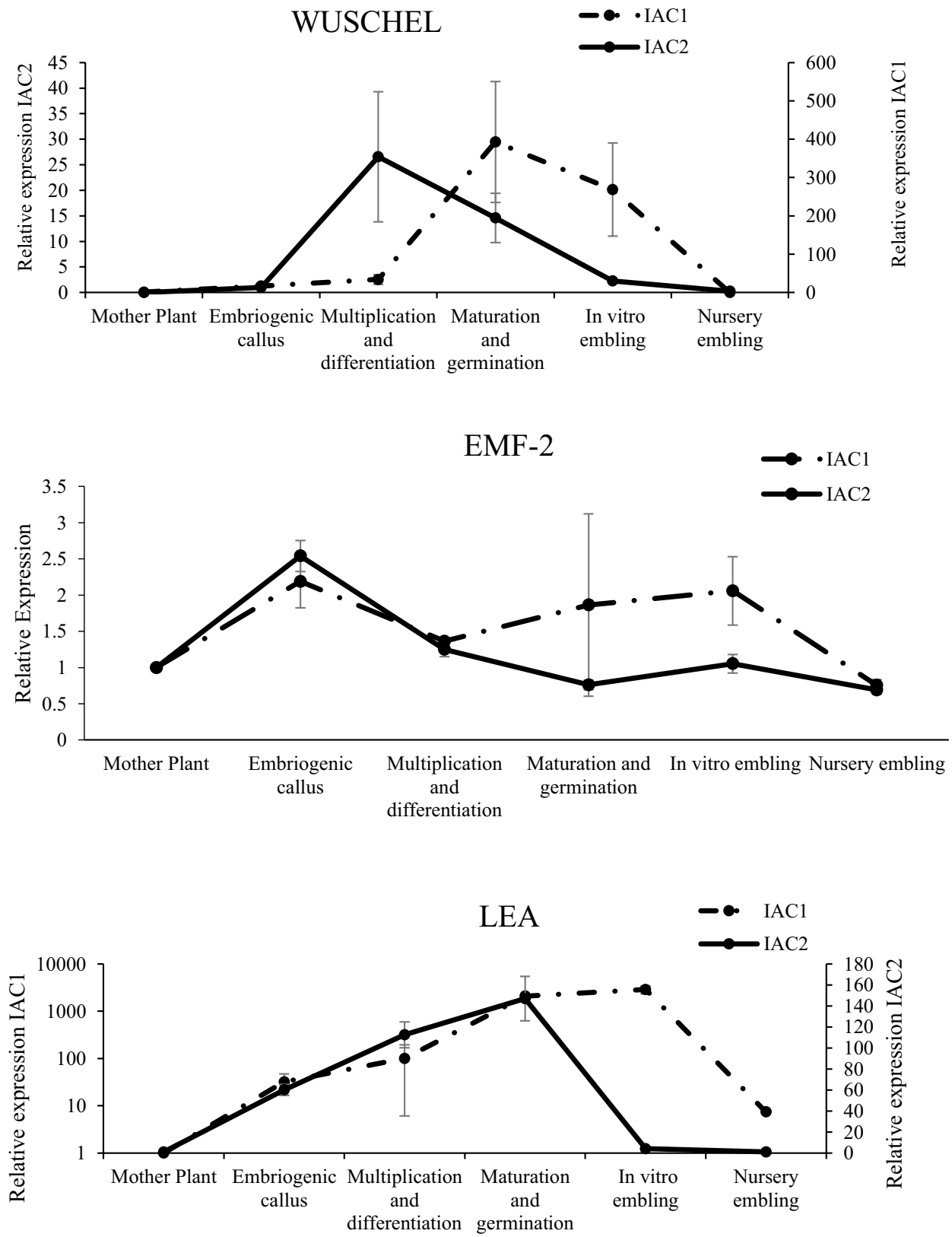

observed on mother plants, suggesting that physiological responses may be stable in clonal plants (Table 3 ). The major exception is for DNAmet expression on IAC 2 emblings, which exhibits higher transcript levels than mother plants (Table 3, Fig. 2). This pattern could explain the low regeneration efficiency observed for IAC 2 . Other interesting observation was the regular levels for EST1 in both genotypes (Table 3, Fig. 2). Once EST1 acts on the activation of a telomerase enzyme active during senescence, this observation indicates that clonal plants are evolving as expected.

\section{Discussion}

The occurrence of somaclonal variation is a major concern when choosing any tissue culture strategy to multiply desired genotypes. There are several advantages to select this multiplication method for perennial and long-life cycle species such as coffee, including the possibility to explore promising hybrids still segregating for non-target characteristics. However, a high level of somaclonal variation could ruin a potential genotype. In coffee, studies 
Fig. 4 Relative quantification of gene expression along SE process considering Mother Plant as the calibrator stage for each genotype. Examples of genes displaying incomparable profiles
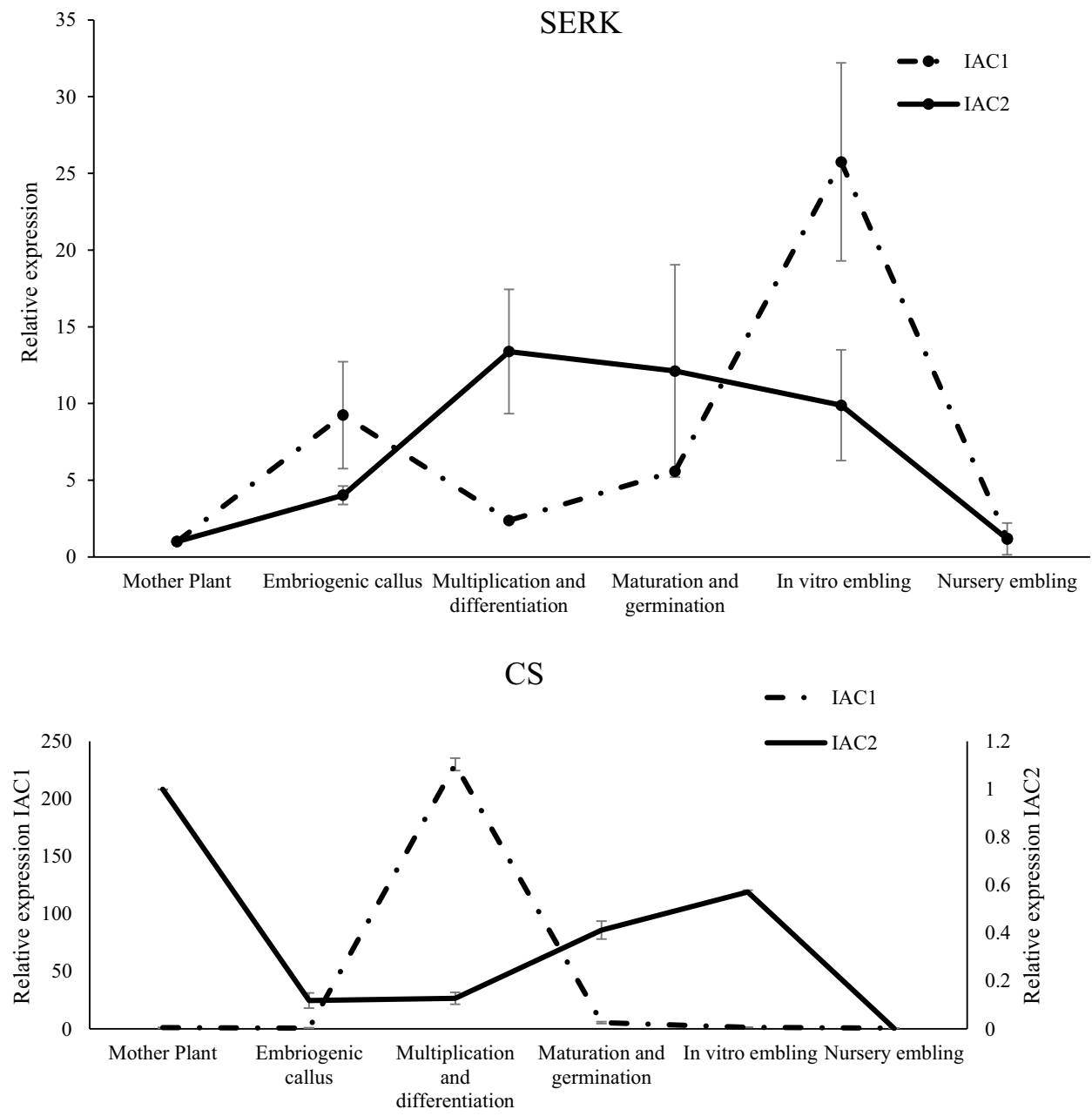

using molecular markers to compare $C$. arabica hybrids and their corresponding emblings indicated very low rates of somaclonal variation (Landey et al. 2013). Although this observation is an encouragement to use in vitro culture, the evaluation of emblings is important to assess the uniformity of the observed response on other genetic backgrounds.

The somatic embryogenesis involves steps of calluses tissue formation and differentiation, re-organization of competent cells to re-differentiate into specific cells, and, finally, the development of clone identical to the mother plant. Here, we selected candidate genes from different biological processes for gene expression analysis aiming to understand the molecular basis of somatic embryogenesis on coffee. Selected pathways include those related to DNA integrity maintenance, cell division and cell cycle control, organ development and plant regeneration, and response to oxidative stress derived from in vitro cultivation. For those gene expression analyses, we assessed all stages of somatic embryogenesis, and also mother plants and regenerated emblings.

\section{DNA integrity}

To assess the overall genome integrity and functionality, we selected two genes: DNA met and H2A. The involvement of these genes on epigenetic modifications of genomes makes them ideal targets to uncover occurrences of somaclonal variations. In a study evaluating epigenetic alterations on C. canephora somatic embryogenic tissues, Nic-Can et al. (2013) proposed a model where global DNA methylation and histone modifications control epigenetic changes that, in their turn, control the whole process. The study indicated that embryogenesis-related genes LEC, BBM1, and WOX4 are targets for this epigenetic control.

DNA methyltransferases are responsible for methylation of the $5^{\prime}$ position of the pyrimidine ring from cytosines, which may cause gene silencing (Bowler et al. 2004; Fuchs et al. 2006). The observed increase in DNAmet transcripts level at early development stages of IAC 1 and IAC 2, indicates a high activity of DNA methylation. In addition, the decrease on DNAmet expression at the final stages of in vitro culture suggests a low level of DNA methylation. 
The high levels observed on embryogenic callus are interesting, as high methylation levels may silence a large amount of genes, leaving active at this stage only those genes necessary for cell division and undifferentiated growth. In addition, the high transcript levels observed on IAC 2 emblings may suggest that gene silencing is still undergoing in these young tissues, affecting the other genes than the ones required to maintain cell identity and function. This observation could explain the delay on embryo development from IAC 2 callus compared to IAC 1 (Table 1).

Histones are proteins responsible for chromatin conformation, which possess several biological functions, such as DNA packaging and cell division, besides being responsible for the epigenetic control of gene expression (Bender 2004). Here, the $\mathrm{H} 2 \mathrm{~A}$ expression profile (Table 3 ) is comparable to the one observed for DNAmet (Fig. 2), on both genotypes. This co-linearity of expression shows that both methylation and chromatin condensation are coordinated for gene regulation during the early stages of embryo development. As the expression for both genes decreases at the final stages of cultivation, reaching levels similar to the ones observed on the mother plant, probable epigenetics modifications might be reverted on later developmental stages.

\section{Embryo development and regeneration}

In vitro culture involves two contradictory aspects: first, an undifferentiated growth and maintenance of stem cells; at the end, a regeneration of a fully functional plant identical to the mother. Here, we selected embryogenesis-related genes, SERK and Wuschel, to characterize the first aspect, and the genes AP2 and EMF-2 for the second aspect.

The expression profile of genes CELL and CELL DIV (Table 3) implies an intense activity of cell multiplication during the embryogenic callus and multiplication stages, as expected in any SE process. In addition, low $\beta$-TUB transcript levels at these stages suggest that a disorganized growth, which followed by an increase of these transcripts during maturation stages, proposes cell re-organization into specialized tissues. These results demonstrate the progress of a regular SE in both genotypes.

The SERK gene is a traditional marker for somatic embryogenesis, and its expression indicates a totipotent cell state (Talapatra et al. 2014). In coffee, expression analyses of an orthologous SERK gene on embryogenic cells indicated that it might be a reliable marker for embryogenic potential of genotypes (Silva et al. 2014). In our study, SERK expression occurs mostly during in vitro culture, and both mother plants and emblings have very reduced transcript levels (Fig. 4), indicating a shift from a totipotent to a differentiate cell state. The expression pattern, however, varies between the cultivars, and may reflect the different potential for SE of each genotype.
Wuschel is a member of a homeobox gene family associated with stem cell and embryogenic status maintenance (Taiz and Zeiger 2009). In somatic embryos of C. canephora, WOX-4, a Wuschel-related gene, has an expression profile similar to the ones observed in this study (Nic-Can et al. 2013); there is no transcript accumulation in mother plants and emblings, the higher expression level occurs during the callus stages, and the levels decrease as the embryogenic tissue differentiates (Fig. 3). These results confirm the role of Wuschel expression as an activator of callus formation and maintenance (ArroyoHerrera et al. 2008). In our study, we observed differences on both the accumulation profile and relative amount of Wuschel transcripts between genotypes. Transcript levels are significantly lower on IAC 2 embryogenic tissues and peak at an early stage compared to transcript profile on IAC 1 (Fig. 3). This profile may indicate a deficiency of IAC 2 on callus maintenance and differentiation, which explain its overall lateness and lower productivity.

The genetic origin may also account for differences on SERK and Wuschel expression values and overall embryogenesis response. IAC 1 and IAC 2 are hybrids of $C$. arabica crossed with C. canephora and C. racemosa, respectively. $C$. canephora is a very robust species, resistant to several pathogens, highly productive, and submitted to intense breeding (Alkimin et al. 2018; Ferrão et al. 2017;). On the other hand, C. racemosa is resistant to leaf miner, drought tolerant, but, with a poor cup quality, its use in breeding programs is limited (Guerreiro-Filho 2006; Guerreiro-Filho et al. 1999). In this context, C. canephora genotypes are genetically more uniform compared to $C$. racemosa ones, and, therefore, may result on hybrids more physiologically balanced. In addition, as $C$. arabica is an allotetraploid species, resulting from a natural hybridization between $C$. eugenioides and C. canephora, crosses with this last species are genetically compatible and, thus, more stable.

Differentiation of embryogenic tissues onto reproductive organs results from a genetic control, which include AP2 and EMF-2 expression. Both genes regulate organ morphogenesis and reproductive identity (Cang-Hsien et al. 1995). Our results show decrease of AP2 expression during SE, and re-activation in later stages, when reproductive organs develop. As observed with Wuschel, AP2 expression increases intensively on IAC 2 emblings, suggesting an unbalanced gene control at this stage. The gene EMF-2 has a similar behavior in both IAC 1 and IAC 2 , with increasing expression on embryogenic callus and multiplication and differentiation phase, indicating that reproductive tissues may be under development. Results from both genes are in accordance with a healthy path towards plant regeneration. 


\section{Response to stress}

In the same way to any in vitro cultivation, SE represents a source of stress to cells due to the continuous control of growth under specific conditions of nutrition, space, and differentiation. A strong response to these stresses may result in poor recovery of healthy plants. Here, we considered the expression patterns of LEA, OXIRED, PPO, EST, and IA to measure the strength of stress response.

LEA-related genes are a family of proteins associated with desiccation processes, such as these occurring during seeds and embryo development. Dussert et al. (2018) carried out an integrative study through genomic and microarray analyses of LEA accumulation during $C$. arabica seed development, a physiological process comparable to embryogenic cultivation. Although those authors could not explain how the LEAs contribute to the desiccation tolerance required on these processes, they reported a dramatic transcription switch characterized by the up-regulation of genes encoding LEA proteins with the acquisition of desiccation tolerance in embryos and endosperms of coffee seeds. In our study, LEA transcripts accumulate increasingly during the cultivation demonstrating the desiccation stress undergone by cultured cells (Fig. 3, Table 3). However, the decreasing on transcript levels at embling stages implies a full cell recovery. An interesting observation is that IAC 1 mother plant presented more than 30 times relative amount of LEA transcripts than IAC 2 at SE maturation and germination stage, and transcript accumulation extended until the nursery embling stage. We expected this behavior on IAC 2, which genetic background has C. racemosa, a species known for its drought tolerance and, therefore, likely associated with high expression of genes related to desiccation response. On the other hand, the LEA expression profile could also indicate an excessive stress response of IAC 1 emblings. In accordance to a normal stress response, expression of OXIRED, an oxidative stress-related gene, is low during the whole SE process (Table 3).

The PPO encodes polyphenol oxidase, an enzyme involved in several stress responses, and, therefore, represents an important marker for this. Here, PPO transcript levels increase during the in vitro embling stage, indicating a significant stress during acclimation period. However, the decreasing of transcript levels in the following stage indicates a recovery of their regular condition.

Another important aspect related to stress is the tissues and organs' overall survive condition. Here, we assess this aspect by evaluating EST and IA gene expression pattern. The EST transcript levels, a gene associated with telomeres integrity and cell aging, remain stable and at similar levels as those on mother plants (Fig. 2, Table 3), suggesting that in vitro culture has no impact on tissue age.
Similar results were observed for IA expression, a gene related to apoptosis (Table 3). Together, those results represent a positive indication which the SE does not lead to either intense stress or precocious senescence of coffee tissues.

Finally, the maintenance of desired traits, such as the defense response to biotic stress of IAC 1 and IAC 2 and overall quality, is also an important aspect to evaluate on clonal coffee plants. Here, we considered expression pattern of EDS, JAZ, and PPT as markers to assess the potential defense response of clonal plants, and CS as marker of caffeine synthesis, the most known coffee component. Transcript accumulation on clonal plants of IAC 1 and IAC 2 is similar to mother plants for PPT, but lower for EDS and JAZ (Table 3). These genes are responsive to biotic stimulus and play important roles during stress and JA-mediated response (Devoto and Turner 2003). The observed differences suggest that the emblings are not as stressed as their mother plants, probably because they were growing under protected conditions. Further assays are under analysis to evaluate the response to biotic stress. The CS accumulation patterns are very irregular. Neither clonal emblings exhibit similar levels to mother plants, nor the expression pattern is consistent during SE (Fig. 4; Table 3). Once caffeine synthesis occurs on coffee young tissues, these results are intriguing, and an evaluation of caffeine levels on older clonal plants will confirm if these observations result from somaclonal variation. Therefore, a continuous evaluation of clonal plants is important to understand the effect of somatic embryogenesis on agronomic traits.

Based on the analyses here, we concluded that, despite the observed variations in gene expression during the process of indirect somatic embryogenesis in coffee, evaluated plants and clones showed the same pattern of expression for most of the studied genes. Those patterns suggest a genomic stability of clone plants and validating this methodology for coffee multiplication.

Author contribution statement OGF, LP, and MPM conceived the work. KCO, PSG, JMB, JCM, and MMS performed the analyses. PSG, JMB, and MPM wrote the manuscript. OGF and LP revised the manuscript. All authors read and approved the final manuscript.

Acknowledgements The Grant 02.13.02.019.00.04 from Consorcio Pesquisa Café (Coffee Research Consortium) supported this work. MPM and OGF are recipients of research fellowships from $\mathrm{CNPq}$ (National Counsel of Scientific and Technological Development). 


\section{Compliance with ethical standards}

Conflict of interest We declare no potential interest conflicts associated with this study.

Human and animal rights There is no involvement of humans and animals. We consent access to our original data upon request.

\section{References}

Alkimin ER, Caixeta ET, Sousa TV, Silva FL, Sakiyama NS, Zambolim L (2018) High-throughput targeted genotyping using nextgeneration sequencing applied in Coffea canephora breeding. Euphytica 214:50

Altschul SF, Gish W, Miller W, Myers EW, Lipman DJ (1990) Basic local alignment search tool. J Mol Biol 215(3):403-410

Arroyo-Herrera A, Ku Gonzalez A, Canche Moo R, Quiroz-Figueroa FR, Loyola-Vargas VM, Rodriguez-Zapata LC, Rodriguez-Zapata C, Burgueff D'Hondt VM, Suárez-Solis EC (2008) Expression of WUSCHEL in Coffea canephora causes ectopic morphogenesis and increases somatic embryogenesis. Plant Cell Tissue Organ Cult 94:171-180. https://doi.org/10.1007/s11240-008-9401-1

Bender J (2004) DNA methylation and epigenetics. Annu Rev Plant Biol 55:41-68

Bertrand B, Alpizar E, Lara L, Santa-Creo R, Hidalgo M, Quijano JM, Montagnon C, Georget F, Etienne H (2011) Performance of Coffea arabica F1 hybrids in agroforestry and full-sun cropping systems in comparison with American pure lines cultivars. Euphytica 181:147-158

Bowler C, Benvenuto G, Laflamme P, Molino D, Probst AV, Tariq M, Paskowski J (2004) Chromatin techniques for plant cells. Plant J 39:776-789

Cang-Hsien YAN, Cen LJ, Sung ZR (1995) Genetic regulation of shoot development in Arabidopsis: role of the EMF genes. Dev Biol 169:421-435

Devoto A, Turner JG (2003) Regulation of jasmonate-mediated plant responses in Arabidopsis. Ann Bot 92:329-337

Donato VMTS, Andrade AG, Cabral JB, Alves GD (2000) Embriogênese somática in vitro em couve-comum. Pesqui Agropecu Bras 35(4):711-718

Dussert S, Serret J, Bastos-Siqueira A, Morcillo F, Déchamp E, Rofidal V, Lashermes P, Etienne H, Joët T (2018) Integrative analysis of the late maturation programme and desiccation tolerance mechanisms in intermediate coffee seeds. J Exp Bot 69(7):1583-1597

Ferrão LFV, Ferrão RG, Ferrão MAG, Francisco A, Garcia AAF (2017) A mixed model to multiple harvest-location trials applied to genomic prediction in Coffea canephora. Tree Genet Genomes 13:95

Fuchs J, Demidov D, Houbem A, Schubert I (2006) Chromosomal histone modification patterns-from conservation to divertsity. TRENDS Plants Sci 11:199-208

Gaj MD (2004) Factors influencing SOMATIC embryogenesis induction and plant regeneration with particular reference to Arabidopsis thaliana (L.) Heynh. Plant Growth Regul 43:27-47

Guerreiro-Filho O (2006) Coffee leaf miner resistance. Braz J Plant Physiol 18:109-117
Guerreiro-Filho O, Silvarolla MB, Eskes AB (1999) Expression and mode of inheritance of resistance in coffee to leaf miner Perileucoptera coffeella. Euphytica 105(1):7-15

Landey BR, Cenci A, Georget F, Bertrand B, Camayo G, Dechamp E, Herrera JC, Santoni S, Lashermes P, Simpson J, Etienne H (2013) High genetic and epigenetic stability in Coffea arabica plants derived from embryogenic suspensions and secondary embryogenesis as revealed by AFLP, MSAP and the phenotypic variation rate. PLoS One 8(2): 56372

Maluf MP, Silva CCD, Oliveira MDPAD, Tavares AG, Silvarolla MB, Guerreiro Filho O (2009) Altered expression of the caffeine synthase gene in a naturally caffeine-free mutant of Coffea arabica. Genet Mol Biol 32(4):802-810

Menéndez-Yuffá A, Barry-Etienne D, Bertrand B, Georget F, Etienne $\mathrm{H}$ (2010) A comparative analysis of the development and quality of nursery plants derived from somatic embryogenesis and from seedlings for large-scale propagation of coffee (Coffea arabica L.). Plant Cell Tissue Organ Culture 102:297-307

Nic-Can GI, Lopez-Torres A, Barredo-Pool F, Wrobel K, Loyola-Vargas VM, Rojas-Herrera R, De-la-Pena C (2013) New insights into somatic embryogenesis: IEAFY COTYLEDON1, BABY BOOM1 and WUSCHEL RELATED HOMEOBOX4 are epigenetically regulated in Coffea canephora. PLoS One 8(8):e72160. https:// doi.org/10.1371/journal.pone.0072160

Pereira AR et al (2007) Embriogênese somática direta em explantes foliares de Coffea arabica L. cv. Acaiá cerrado: efeito de cinetina e ácido giberélico. Ciência e Agrotecnologia Lavras 31(2):332-336

Phillips RL, Kaeppler SM, Olhoft P (1994) Genetic instability of plant tissue cultures: breakdown of normal controls. Proc Natl Acad Sci 91:5222-5226

SBW do Brasil—Rodovia SP (2018) 107-Km 32-Holambra/SP/ BRASIL-CEP 13.825-000 Copyright $\odot 2018$ SBW do BRASIL. http://www.sbwbrasil.com.br/

Shahzad A, Sharma S, Parveen S, Saeed T, Shaheen A, Akhtar R, Ahmad Z (2017) Historical perspective and basic principles of plant tissue culture. In: Abdin MZ, Kiran U, Kamaluddin M, Ali A (eds) Plant biotechnology: principles and applications. Springer, Singapore, pp 1-36

Silva AT, Barduche D, do Livramento KG, Ligterink W, Paiva LV (2014) Characterization of a putative serk-like ortholog in embryogenic cell suspension cultures of Coffea arabica L. Plant Mol Biol Rep 32:176-184. https://doi.org/10.1007/s11105-013-0632-x

Taiz L, Zeiger E (2009) Fisiologia Vegetal. Ed. 4. Artmed, Porto Alegre, p 819

Talapatra S, Ghoshal N, Raychaudhuri SS (2014) Molecular characterization, modeling and expression analysis of a somatic embryogenesis receptor kinase (SERK) gene in Momordica charantia L. during somatic embryogenesis. Plant Cell Tissue Organ Cult 116(3):271-283

Vieira LGE et al (2006) Brazilian coffee genome Project: eST-based genomic resource. Braz J Plant Physiol 18:95-108

Publisher's Note Springer Nature remains neutral with regard to jurisdictional claims in published maps and institutional affiliations. 